\title{
Mental health of refugees: global perspectives
}

\author{
Mohammed T. Abou-Saleh ${ }^{1}$ and George N. Christodoulou ${ }^{2}$
}

'Professor of Psychiatry, St George's, University of London, UK, email mabousal@ gmail.com

2Professor Emeritus of Psychiatry, University of Athens Medical School, Athens, Greece, email profgchristodoulou@gmail.com
Refugees have high rates of mental health morbidity as a result of conflict. However, their needs for mental healthcare and psychosocial support are often unmet, despite the efforts of professional and humanitarian organisations. The war refugee crisis is a global challenge that needs a global solution. We call on all governments, regional and international organisations to take responsible humanitarian actions to intervene and support people affected by these disasters and for all humanity to unite against the forces of injustice and degradation. The thematic papers in this issue report on the Syrian crisis from a variety of perspectives.

The Office of the United Nations High Commissioner for Refugees (UNHCR) has recently reported that global forced displacement increased in 2015 to record-high numbers. By the end of the year, 65.3 million individuals had been forcibly displaced worldwide as a result of persecution, conflict, generalised violence or human rights violations. The highest numbers of refugees were from Syria (4.9 million), over half of them children (UNHCR, 2015).

Refugees' basic needs of security, food, housing and other social needs are often not met, despite all the efforts of the World Health Organization (WHO), UNHCR, non-governmental organisations (NGOs) and other humanitarian organisations. The prime issue of health security is an even greater difficulty in populations in transit from low-income countries afflicted by war to countries in no better state of social and economic development. Refugees can pose extreme challenges to their health and social care systems, as has been witnessed in the Syrian conflict with the millions of refugees in Turkey and Lebanon, as discussed in this issue, as well as Jordan.

The following articles on mental health of Syrian refugees capture the mental health issues and the challenges that face all concerned in the provision of essential mental health and psychosocial support services (MHPSS).

The article by Almoshmosh and colleagues from the Syrian Association for Mental Health (SAMH) highlights the serious mental health consequences for Syrian refugees (including children) beyond post-traumatic stress disorder (PTSD), set against the limited provision of MHPSS, the pivotal role of NGOs and the poor coordination of these essential services. The focus is on the need for community services and enforcement of the prime resource of resilience, self-management and promoting recovery. SAMH has risen to the challenges in contributing to essential MHPSS and training for healthcare professionals in evidencebased interventions.

The article by Hughes and colleagues is focused on improving access to mental healthcare for displaced Syrians, with case studies from Syria, Iraq and Turkey. They used the mhGAP Intervention Guide, the tried and tested package for training general health professionals in community-based integrated approaches to the provision of mental healthcare through primary care.

The article by Karam and colleagues examines mental health system reform in Lebanon and the Syrian crisis, and outlines an innovative collaborative model of care. The authors describe the positive experience of the Ministry of Public Health of establishing an MHPSS task force that coordinates the work of more than 62 actors working within the Syrian crisis response in Lebanon through a common annual action plan for all. As documented, the action plan is implementing several cost-effective and evidence-based strategic interventions. Moreover, the authors report valuable data on the prevalence of mental disorder in Syrian refugee children and adolescents. A key finding is that childhood adversity is more important a determinant than exposure to trauma in the occurrence of mental ill-health, particularly PTSD. A classroom-based intervention has been developed and piloted in schools, targeting children to build their resilience and coping strategies.

Research on the mental health of Syrian refugees should focus on three priorities: strengthening routine mental health programme monitoring and evaluation, rather than resourceintensive, primary epidemiological work on the prevalence of mental disorder; implementation research focused on testing interventions; and the potential role of self-efficacy in managing psychological stress (Abbara et al, 2016).

\section{Health as a weapon of war}

It is tragic that health is sometimes used as a weapon of war and healthcare services and staff are targeted in the conflict, resulting in the exodus of scarce healthcare workers as refugees.

Médecins Sans Frontières (MSF), documenting the war wounded and war dead in MSF-supported medical facilities in Syria in 2015, reported that 94 aerial and shelling attacks had hit 63 medical facilities, causing varying degrees of damage, and in 12 cases the total destruction of the facilities and the death or wounding of 81 MSF-supported 
medical staff. MSF called on all the military forces to respect international humanitarian law (MSF, 2015).

\section{Mental health of refugees}

Refugees have serious healthcare needs, including communicable and non-communicable diseases. However, the true treatment gap is in the provision of MHPSS.

Studies on the mental health of refugees and displaced persons in Syria and surrounding countries suggest rising levels of psychosocial distress. Coverage of MHPSS for internally displaced people and refugees in difficult-to-access areas is minimal. In light of the ongoing violence, demand for culturally appropriate services is expected to grow (Abou-Saleh \& Hughes, 2015).

There is a limited evidence base for effective MHPSS in humanitarian settings: research has focused on interventions that are infrequently implemented, whereas the most commonly used interventions have had little rigorous scrutiny ( Tol et al, 2011).

A recent systematic review of long-term studies of the mental health of war refugees showed that at least one in five suffer from depression, PTSD or anxiety disorder, and that greater exposure to pre-migration traumatic experiences and postmigration stress were the most consistent factors associated with all three disorders, while poor post-migration socioeconomic status was particularly associated with depression (Bogic et al, 2015). These findings have implications for the long-term care of war refugees and the need to alleviate their post-migration socioeconomic adversity, which has been shown in a Sri Lankan population to diminish their resilience more strongly and robustly than the presence of mental disorder (Siriwardhana et $a l, 2015)$.

\section{International action}

Against this background, we consider global perspectives on the mental health of refugees and international action.

The WHO issued the Inter-Agency Standing Committee (IASC) guidelines in 2007 to enable humanitarian actors to plan, establish and coordinate a set of minimum multisectoral responses to protect and improve MHPSS in the midst of an emergency, whether natural or man-made. However, the guidelines have not been universally or uniformly used or applied.

The UNHCR concluded that:

while the majority of MHPSS activities are delivered by implementing partners, UNHCR staff require familiarity with core principles in the field, such as the Intervention Pyramid contained in the IASC guidelines, in order to support and monitor quality MHPSS activities. (UNHCR, 2013)

A systematic review of the effectiveness of mechanisms and models of coordination between organisations, agencies and bodies providing or financing health services in humanitarian crises provided very low-quality evidence of their effectiveness in information coordination and management/directive coordination (Akl et al, 2015).

A landmark development was the adoption of the WHO's Comprehensive Mental Health Action Plan 2013-2020 by the 66th World Health Assembly. The Action Plan proposed that member countries work with national emergency committees and mental health providers.

The WHO has recently adapted its mhGAP Intervention Guide. The mhGAP Humanitarian Intervention Guide provides first-line management recommendations for psychiatric, neurological and substance use conditions for non-specialist healthcare providers in humanitarian emergencies, including armed conflict, where access to specialists and treatment is limited (WHO, 2015).

It is of concern that the International Organization for Migration, the leading intergovernmental organisation in the field of migration, which works closely with governmental, intergovernmental and non-governmental partners, has not sufficiently attended to the mental health needs of migrants in its medical assessment protocols for people who have been accepted for resettlement in other countries.

The World Federation for Mental Health (WFMH), the international mental health advocacy organisation, has launched the People's Charter for Mental Health on behalf of civil society and NGOs and called for the WHO's Comprehensive Mental Health Action Plan to be implemented expeditiously by all countries and for mental health to be represented on all disaster emergency committees (WFMH, 2013).

\section{A call for global action}

The war refugee crisis is a global challenge that needs a global solution. The World Psychiatric Association (2016) has called on all governments to act with promptness and fairness in assessing, screening and deciding on the legal status of migrants in order to reduce uncertainty and provide physical and emotional support as needed. The potential new host countries must be reassured and supported, their fears and concerns addressed.

We endorse the WFMH's declarations, particularly the 2015 Cairo Declaration on the Mental Health of Refugees, Internally Displaced Persons and Other Populations Affected by Conflict and the 2016 Anti-war Declaration of Athens, endorsed by more than 100 organisations, because it is clear that war is a major contributor to refugee crises and their mental health consequences (Society of Preventive Psychiatry, 2016).

Amnesty International declared that the world's system for protecting refugees is broken and it has put forward solutions for how world leaders - in particular the richest countries - can start tackling this global humanitarian crisis together. Governments have a duty to help refugees but most rich countries are still treating refugees as somebody else's problem. Fearing being 'flooded', they have 
allowed poorer, countries, mainly Middle Eastern, African and South Asian, to host the vast majority of refugees. Their initiative should involve setting up strong refugee systems: allowing people to apply for asylum, treating their refugee claims fairly, resettling the most vulnerable of all and providing basics like education and healthcare.

In the words of Martin Luther King:

Injustice anywhere is a threat to justice everywhere. We are caught in an inescapable network of mutuality, tied in a single garment of destiny. Whatever affects one directly, affects all indirectly.

The Syrian catastrophe is a failure of humanity and the need for action is now. Syria was the cradle of civilisation and should not become its grave.

\section{References}

Abbara, A., Coutts, A., Fouad, M. F., et al (2016) Mental health among displaced Syrians: findings from the Syria Public Health Network. Journal of the Royal Society of Medicine, 109(3), 88-90.

Abou-Saleh, M. T. \& Hughes, P. (2015) Mental health of Syrian refugees: looking backwards and forwards. Lancet Psychiatry, 2, 870-871.

Akl, E. A., El-Jardali, F., Bou Karroum, L., et al (2015) Effectiveness of mechanisms and models of coordination between organizations, agencies and bodies providing or financing health services in humanitarian crises: a systematic review. PLoS One, 10(9), e0137159.

Bogic, M., Njoku, A. \& Priebe, S. (2015) Long-term mental health of war-refugees: a systematic literature review. BMC International Health and Human Rights, 15, 29.
MSF (2015) Syria 2015: Documenting War-Wounded and War-Dead in MSF-Supported Medical Facilities in Syria. Available at https:// www.doctorswithoutborders.org/sites/usa/files/syria_2015 wardead_and_war-wounded_report_en.pdf (accessed 1 September 2016).

Siriwardhana, C., Abas, M., Siribaddana, S., et al (2015) Dynamics of resilience in forced migration: a 1-year follow-up study of longitudinal associations with mental health in a conflict-affected, ethnic Muslim population. BMJ Open, 5(2), e006000.

Society of Preventive Psychiatry (2016) Anti-war Declaration of Athens. Available at http://www.psychiatricprevention.com (accessed 1 September 2016).

Tol, W. A., Barbui, C., Galappatti, A., et al (2011) Mental health and psychosocial support in humanitarian settings: linking practice and research. Lancet, 378, 1581-1591.

UNHCR (2013) Mental Health and Psychosocial Support for Persons of Concern. Available at http://www.unhcr.org/51bec3359.pdf (accessed 1 September 2016).

UNHCR (2015) Global trends. At http://www.unhcr.org/en-us/ statistics/unhcrstats/576408cd7/unhcr-global-trends-2015.html (accessed 1 September 2016).

UNICEF (2012) Syria's Children: A Lost Generation? Available at http://www.unicef.org.hk/upload/NewsMedia/publication/ Syria_2yr_Report.pdf (accessed 1 September 2016).

WFMH (2013) People's Charter for Mental Health. Available at http://staging.wfmh.com/wp-content/uploads/2014/02/THEPEOPLES-CHARTER-2013.pdf (accessed 1 September 2016).

WHO (2015) mhGAP Humanitarian Intervention Guide (mhGAP. HIG) Available at http://www who.int/mental_health/publications/ mhgap_hig/en (accessed 1 September 2016).

World Psychiatric Association (2016) Position Statement on Europe's Migrant and Refugee Crisis. WPA.

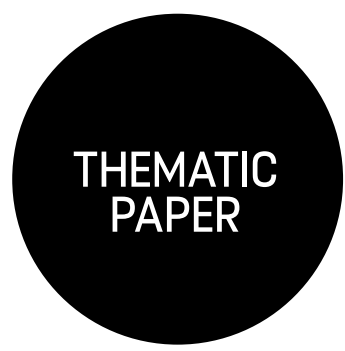

\title{
Mental health and psychosocial needs of Syrian refugees and the role of Syrian non-governmental organisations
}

\author{
Nadim Almoshmosh, ${ }^{1}$ Mamoun Mobayed ${ }^{2}$ and Mohammad Aljendi ${ }^{3}$
}

${ }^{1}$ Consultant Psychiatrist, Global Medics, UK, emal nalmoshmosh@gmail. ${ }^{2}$ Consultant Psychiatrist, Behavioral Healthcare Center in Doha, Qatar

${ }^{3}$ Consultant Psychiatrist, Al Amal Complex for Mental Health, Jeddah, Saudi Arabia

Declaration of interest: All authors work closely with Syrian refugees and are members of the Syrian Association for Mental Health (SAMH).
Almost 5 million Syrians have been registered as refugees since the conflict started in 2011. Their mental health and psychosocial needs continue to grow as the situation at home gets more complicated. Syrian nongovernmental organisations (NGOs) and mental health professionals have been offering their support to help meet these needs. They have set up various centres and teams on the ground that focus their efforts on the most needy individuals. They train and supervise healthcare volunteers, encourage self-management and build on people's resilience. These NGOs require support to deal with the consequences of this unprecedented crisis.
Civil demonstrations that began in March 2011 were met with force which escalated into a civil war that now is in its sixth year. Millions of Syrians, almost half the Syrian population, have been displaced either internally or as refugees in neighbouring countries and beyond. The number of registered refugees recorded by the Office of the United Nations High Commissioner for Refugees (UNHCR) now stands at 4.8 million, with just under half a million of these being resident in camps (data from the UNHCR portal, http://data. unhcr.org, August 2016). As is often the case in armed conflicts, civilians are the main victims, and we highlight here their mental health and psychosocial needs along with the response from Syrian non-governmental organisations (NGOs). 